ИЗВЕСТИЯ АКАДЕМИИ НАУК ЭСТОНСКОП ССР. ТОМ 29

ГЕОЛОГИЯ. 1980, № 4

\title{
ОЦЕНКА СРЕДНЕГО ПОКАЗАТЕЛЯ ЗАЛЕЖИ МЕСТОРОЖДЕНИЯ НА ОСНОВЕ ПОЛИНОМИАЛЬНОЙ АППРОКСИМАЦИИ
}

Известным методом восстановления полей геологических показателей является полиномиальная аппроксимация. Однако полиномы высоких порядков оказываются неустойчивыми, что снижает их практическую ценность.

Мы изучили названную проблему (Оргла, 1978), определяя параметры уравнения, как обычно, по методу наименьших квадратов с помощью матричного уравнения

$$
\vec{b}=\left(\overrightarrow{Z^{\prime} Z}\right)^{-1} \overrightarrow{Z^{\prime}} \vec{P}
$$

где $\vec{b}-$ вектор параметров, $\vec{Z}-$ матрица независимых переменных, $\vec{P}$ - вектор зависимой переменной.

Наши исследования показали, что область применимости метода расширяется, если исходные наблюдения нормировать, использовать при построении матрицы $\vec{Z} \cdot \vec{Z}$ и вектора $\overrightarrow{Z^{\prime}} \vec{P}$ рекуррентных уравнений, матрицу $\overrightarrow{Z^{\prime}} \vec{Z}$ преобразовать перед обращением в корреляционную матрицу.

В настоящей статье изучены возможности применения полиномов разных порядков, реализованные на ЭВМ по изложенному алгоритму, для оценки среднего показателя залежи на примере торфяного месторождения.

Как известно, при качественной оценке запасов торфяных залежей вычисление средних показателей обычно производится путем вычисления простого арифметического среднего их значения. С построением устойчивой четырехмерной модели на ЭВМ возникает реальная возможность осуществить на практике идею А. М. Журавского (1940). Согласно его идее, если бы нам были известны функции размещения изучаемого показателя и конфигурации месторождения, то весь ход нахождения среднего сводился бы к простой аналитической операции вычисления объемного интеграла. В соответствии с этим, если мы имеем возможность построить четырехмерную модель или, другими словами, если нам известна функция изменения изучаемого показателя в торфяной залежи, то мы можем получить его пространственно взвешенное среднее содержание $\left(P_{\text {вз }}\right)$ путем вычисления объемного интеграла модели и деления результата интегрирования на объем.

Мы применяли в качестве исходной модели для получения средневзвешенных значений свойств торфа полином 


\section{Ведомость послойных значений зольности в прямоугольном блоке месторождения Пухату (см. рисунок)}

\begin{tabular}{|c|c|c|c|c|c|c|c|}
\hline \multirow{2}{*}{$\begin{array}{l}\text { Глубина } \\
\text { слоев, } M\end{array}$} & \multicolumn{7}{|c|}{ Номера пунктов опробования } \\
\hline & 1 & 2 & 3 & 4 & 5 & 6 & 7 \\
\hline $\begin{array}{l}0,25 \\
0,50 \\
0,75 \\
1,00 \\
1,25 \\
1,50 \\
1,75 \\
2,00 \\
2,25 \\
2,50 \\
2,75 \\
3,00\end{array}$ & $\begin{array}{r}7,2 \\
5,8 \\
6,0 \\
6,4 \\
6,9 \\
6,3 \\
7,0 \\
6,9 \\
6,8 \\
8,2 \\
10,4 \\
11,9\end{array}$ & $\begin{array}{r}7,5 \\
4,5 \\
5,2 \\
14,6 \\
5,7 \\
5,8 \\
5,6 \\
4,9 \\
5,7 \\
6,7 \\
5,8 \\
18,7\end{array}$ & $\begin{array}{l}6,3 \\
5,3 \\
5,6 \\
5,7 \\
6,1 \\
5,5 \\
5,8 \\
7,0 \\
6,9 \\
7,6 \\
8,4 \\
9,1\end{array}$ & $\begin{array}{l}7,4 \\
5,4 \\
4,9 \\
5,0 \\
4,8 \\
5,0 \\
7,4 \\
5,0 \\
5,2 \\
6,2 \\
6,1 \\
7,2\end{array}$ & $\begin{array}{l}5,8 \\
4,3 \\
4,9 \\
4,8 \\
4,5 \\
4,5 \\
4,5 \\
4,9 \\
5,5 \\
5,4 \\
8,1 \\
9,2\end{array}$ & $\begin{array}{l}6,5 \\
4,8 \\
4,9 \\
4,2 \\
5,3 \\
3,6 \\
5,2 \\
5,8 \\
5,4 \\
6,2 \\
6,1 \\
6,7\end{array}$ & $\begin{array}{r}6,7 \\
4,5 \\
4,3 \\
4,9 \\
4,4 \\
5,1 \\
5,0 \\
4,6 \\
5,5 \\
5,5 \\
6,9 \\
12,0\end{array}$ \\
\hline
\end{tabular}

где $P$ - изучаемый показатель;

$X, Y, W$ - независимые переменные (декартовы координаты точки);

$c_{r r^{\prime} r^{\prime \prime}}$ - оценки параметров $\gamma_{r r^{\prime} r^{\prime \prime}}$ (Оргла, 1978);

$\varepsilon-$ ошибка.

Аналогично вычислению массы неоднородного тела в физике (Яворский, Детлаф, 1974) объемный интеграл качественного показателя торфяного месторождения получается путем трехкратного интегрирования функции (1) по области наличия торфа $D$.

$$
\iiint_{D}\left[\sum_{r=0}^{p} \sum_{r^{\prime}=0}^{p-r} \sum_{r^{\prime \prime}=0}^{p-r-r^{\prime}} c_{r r^{\prime} r^{\prime \prime}} X^{r} Y^{r^{\prime}} W r^{r^{\prime \prime}}\right] d D .
$$

Деление результата интегрирования на объем торфяной залежи $V$ в области $D$ дает пространственно взвешенное среднее содержание показателя качества торфа $P_{\text {вз. }}$.

Отметим, что результат интегрирования качественного показателя месторождения не имеет наглядного физического смысла и поэтому интуитивное понимание процедуры определения значения $P_{\text {вз }}$ несколько затруднено.

Проиллюстрируем изложенное на примере исследования зольности в прямоугольном блоке (простейший случай) торфяного месторождения Пухату (рисунок). Исходным материалом для вычисления оценки среднего служили данные детальной разведки опробования на зольность

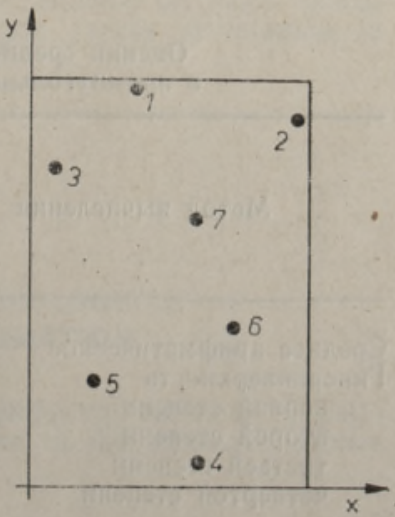


торфяной залежи в блоке в 7 пунктах через интервалы 0,25 м (табл. 1, рисунок). В изучаемом блоке, находящемся на северной части месторождения, представлена только торфяная залежь низинного типа. Мощность болотных отложений в прямоугольном контуре составляет $3,9 \mathrm{M}$.

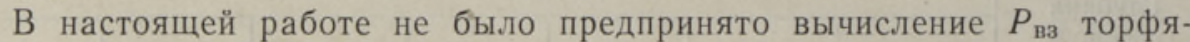
ной залежи на ЭВМ. Из-за громоздкости ручных расчетов мы не ставили перед собой задачу получить средневзвешенную оценку зольности залежи для всего детально разведанного участка, а лишь для прямоугольного блока внутри его. Если ребра блока параллельны осям $X, Y, W$ и исходят с начала координат, то по формуле НьютонаЛейбница (Выгодский, 1969) определенный интеграл (2), деленный на объем, равняется:

$$
P_{\mathrm{B} 3}=\frac{1}{X_{2} Y_{2} W_{2}} \sum_{r=0}^{p} \sum_{r^{\prime}=0}^{p-r} \sum_{r^{\prime \prime}=0}^{p-r-r^{\prime}} c_{r r^{\prime} r^{\prime \prime}} \frac{X_{2}^{r+1} Y_{2}^{r^{\prime}+1} W_{2}^{r^{\prime \prime}+1}}{(r+1)\left(r^{\prime}+1\right)\left(r^{\prime \prime}+1\right)} .
$$

В данном случае процедура расчетов упрощается тем, что вычисление определенного интеграла необходимо не по сложной конфигурации месторождения, а по прямоугольному блоку с координатами $X_{1}=0 \kappa м$, $X_{2}=1,60 \kappa \mu ; Y_{1}=0 \kappa \mu, Y_{2}=2,36 \kappa \mu ; W_{1}=0 \mu, W_{2}=3 \mu$.

В целях уточнения возможностей метода мы рассчитывали по формуле (3) средневзвешенные оценки зольности для участка при различном количестве и неодинаковой степени равномерности пробных пунктов с помощью полинномов до четвертого порядка. Начиная с пятого порядка, модель из-за краевого эффекта оказалась неадекватной и потеряла геологический смысл. Кроме того, мы вычислили для этих же выборок средние арифметические. Результаты расчетов приведены в табл. 2.

Истинная средняя зольность залежи в блоке нам неизвестна. В то же время нет сомнения, что точность оценки повышается с увеличением равномерности распределения и количества пробных пунктов, т. е., в табл. 2 слева направо. Распределение пунктов по площади и их нумерация показаны на рисунке.

Известно, что увеличение порядка гиперповерхности до оптимального приводит к улучшению модели. Поэтому можно считать, что точность оценки среднего значения показателя увеличивается в табл. 2 также сверху вниз. В силу упомянутых закономерностей мы можем

Таблица 2

Оценки среднего значения зольности торфяной залежи (\%) в прямоугольном блоке месторождения Пухату (см. рисунок)

\begin{tabular}{|c|c|c|c|c|}
\hline \multirow{2}{*}{ Метод вычисления } & \multicolumn{4}{|c|}{$\begin{array}{c}\text { Номера пробных пунктов (расположение } \\
\text { см. на рисунке) }\end{array}$} \\
\hline & $1,2,3$ & $\begin{array}{l}1,2,3 \\
4 \text { и } 5\end{array}$ & $1,2,3,4$ & $\begin{array}{l}1,2,3,4, \\
5,6 \text { и } 7\end{array}$ \\
\hline $\begin{array}{l}\text { Среднее арифметическое } \\
\text { Гиперповерхность }\end{array}$ & 6,86 & 6,60 & 6,40 & 6,31 \\
\hline $\begin{array}{l}\text { первой степени } \\
\text { второй степени } \\
\text { третьей степени } \\
\text { четвертой степени }\end{array}$ & $\begin{array}{l}6,25 \\
6,48 \\
6,08 \\
6,31\end{array}$ & $\begin{array}{l}6,02 \\
6,43 \\
6,13 \\
6,18\end{array}$ & $\begin{array}{l}6,01 \\
6,06 \\
5,80 \\
5,89\end{array}$ & $\begin{array}{l}5,90 \\
6,06 \\
5,79 \\
5,94\end{array}$ \\
\hline
\end{tabular}


констатировать, что самыми близкими к истинной средней зольности в залежи на прямоугольном участке являются значения, находящиеся в правом нижнем углу табл. 2 .

Из табл. 2 следует, что средние арифметические характеризуются завышенными значениями по сравнению со средневзвешенными. Это объясняется тем, что фактор равномерности наблюдений оказывает на средние арифметические большое влияние, тем более что все средние вычислены на основе пробных пунктов, густота которых больше в северной части блока, где зольность залежи больше. Если исключить два пункта (1 и 2), расположенные в северной части участка, то плотность наблюдений в южной части повышается и среднее арифметическое составляет $5,82 \%$. Наиболее равномерное распределение пунктов, если учитывать пункты $1,3,4,5,6$ и 7 , дает среднее арифметическое $6,10 \%$.

Таким образом, мы показали, что алгебраические полиномы целочисленной степени могут быть использованы для получения пространственных взвешенных оценок средних значений показателей месторождений. Изложенный метод улучшает качество представленных геологоразведочных материалов, является более экономичным по сравнению с применяемыми в настоящее время методами в планировании разведки полезных ископаемых.

\section{Л И Т Е Р А У Р А}

В ыгодский М. Я. Справочник по высшей математике. М., 1969, 457-459.

Ж у а в ски й А. М. Математическая теория подсчета запасов полезных ископаемых. - Вестн. АН СССР, 1940, 7, 9-13.

Оргла К. А. Полиномиальный анализ тренда мощности залежи для подсчета запасов месторождения на ЭВМ. - Изв. АН ЭССР. Геол., 1978, 27, $27-32$.

Я в о рский Б. М., Де т л а А. А. Справочник по физике. М., 1974, 36-38.
Ннститут геологии
Академии наук Эстонской ССР
Поступила в редакцию $24 /$ III 1980

\section{K. ORGLA}

\section{POLONOMIAALSEL LÄHENDAMISEL POOHINEV MAARDLA LASUNDI NÄITAJA KESKVAARTUSE HINNANG}

Artiklis on esitatud geoloogiliste näitajate keskväärtuse hinnangu arvutusviis, mis pōhineb polünomiaalsel lähendamisel. Et hulkliikme koefitsientide leidmine on väga töömahukas, on sellist arvutusviisi otstarbekas kasutada maavarade varude arvestamise ja hindamise automatiseeritud süsteemis.

K. ORGLA

\section{CALCULATION OF AVERAGES FOR THE GEOLOGICAL VARIABLES BY POLYNOMIAL APPROXIMATION}

The author describes a method for calculating averages of geological variables by polynomial approximation. The method can be effectively realized in the automatic system for calculating the resources and the quality of the deposits. 